\title{
Correction to: China's Intellectual Property Regime for Innovation
}

\section{Correction to:}

D. Prud'homme and T. Zhang,

China's Intellectual Property Regime for Innovation, https://doi.org/10.1007/978-3-030-10404-7

The original version of the book was inadvertently published with an error in the numeral "50,000" and this has been corrected as "500,000" in the chapters "Statutory IP Laws" (Page 36) and "Implications for Policymakers" (Page 217).

The erratum book has been updated with the changes. 